COMMENT. Proton MR spectroscopic imaging (MRSI) will detect neuronal metabolic dysfunction in areas of focal cortical dysplasia defined by MRI and may also demonstrate involvement of surrounding tissue. Different types of cortical developmental malformation, resulting from insults at various stages of cell differentiation and migration, show different degrees of metabolic dysfunction. Imaging techniques that define the structure and metabolism (PET, MRSI) or function (fMRI, EEG) of cortical lesions are important in future investigation of epileptic foci and in studies of the neuroanatomical basis of learning disabilities (See PPN III, 1997;pp 212, 269-276).

Role of transcription factors in the development of the cerebral cortex is reviewed from the Child Study Center, Yale University School of Medicine, New Haven, CT (Leckman JF, Lombroso PJ. I Am Acad Child Adolesc Psychiatry April 1998;37:451-452). Regulatory proteins that recognize and bind with DNA stretches within a promoter region are called transcription factors. These factors are themselves regulated by neurotransmitter signals, initiating the transcription of specific target genes. Mutations within these regulatory proteins can affect a number of organ systems, leading to multiple developmental abnormalities.

\title{
MRI ANALYSIS OF NEUROFIBROMATOSIS TYPE 1
}

Serial MRI scans of 30 patients (mean age, 12 years) with neurofibromatosis Type 1 (NF-1) showed the evolution of high-signal brain lesions in a prospective study at the University of Connecticut Health Center, Farmington, and Children's Medical Center, Hartford, CT. At initial examination, 19 patients had brain lesions identified by MRI, located in the hemisperes in 19, the brainstem in 10 , and cerebellum in 10. Over a mean follow-up interval of 2 to 3 years, a decrease in total number and size of lesions in the hemispheres and cerebellum was noted, whereas brainstem lesions increased in number and size. Mass effect was associated with lesions in the brainstem, thalamus and cerebellar peduncles. Surgery or radiotherapy was required for mass lesions in 3 patients. (DiMario FJ Jr, Ramsby G. Magnetic resonance imaging lesion analysis in neurofibromatosis type 1. Arch Neurol April 1998;55:500-505). (Respond: Francis J DiMario Jr, MD, Department of Pediatrics, Division of Neurology, Connecticut Children's Medical Center, 282 Washington St, Hartford, CT 06106).

COMMENT. High-signal MRI lesions in NF-1 evolve over time. They either increase or decrease in size or number, dependent on the location. Brainstem lesions are likely to increase whereas hemisphere and cerebellar lesions may regress. Correlations between T2-weighted hyperintensities (UBOs) and lower IQs in children with NF-1 have been reported by Denckla MB and others. (See PPN III, 1997;pp 291-294).

\section{ATTENTION DEFICIT AND LEARNING DISORDERS}

\section{LONG-TERM OUTCOME OF ADHD}

The adult outcome of hyperactive boys with attention deficit hyperactivity disorder was evaluated by prospective follow-up and direct psychiatric interviews of 85 probands and 73 comparison subjects at the Child and Adolescent Behavior Center, Long Island Jewish Medical Center, New Hyde Park, NY. The patients had been referred at an average age of 7 years, and they were interviewed at a mean age of 24 years. ADHD had resolved, occurring in only $4 \%$ of probands and none of 
the controls. Antisocial personality disorder (12\% versus $3 \%$ ) and nonalcohol substance abuse $(12 \%$ versus $4 \%)$ were significantly more prevalent among patients than controls. Mood disorders in $4 \%$ and anxiety disorders in $2 \%$ were not significantly different from control prevalences. (Mannuzza S, Klein RG, Bessler A, Malloy P, LaPadula M. Adult psychiatric status of hyperactive boys grown up. Am I Psychiatry April 1998;155:493-498). (Respond: Dr Salvatore Mannuzza, Department of Clinical Psychology, New York State Psychiatric Institute, 722 West 168th St, New York, NY 10032).

COMMENT. Children with uncomplicated ADHD referred to a psychiatric clinic may "outgrow" the symptoms of hyperactivity and inattentiveness but they are at risk of developing antisocial pers nnality and nonalcoholic substance abuse disorders as grown ups. Substance abuse disorders in adults with a history of ADHD have been reported previously, but in association with persistence of ADHD.

Shaffer D, also from the NY State Psychiatric Institute, reported in 1994 that psychoactive substance abuse disorder is commonly associated with diagnoses of ADHD in adults. Biederman J et al, at the Massachusetts General Hospital, found in 1995 that childhood onset ADHD persisting in adults without comorbidity carried a $40 \%$ risk of substance abuse disorders, most commonly marijuana. Risk factors for persistence of ADHD into adolescence included 1) a genetic familiality of ADHD, 2) environmental psychosocial adversity and exposure to parental conflict, and 3) comorbidity with conduct, mood and anxiety disorders. (See PPN III, 1997; pp 231233).

The probands in the NY study did not suffer from the comorbid conduct disorders, common to $30 \%-50 \%$ of children with ADHD seen at psychiatric centers. Follow-up studies of children with ADHD referred to pediatric neurologists would be of interest. Selection of cases based on clinic referral may be important in outcome epidemiological studies of ADHD.

\section{STIMULANT INDUCED TRICHOTILLOMANIA IN ADHD}

The onset or exacerbation of trichotillomania (TT) within 6 months of starting treatment with methylphenidate (dose unreported) for ADHD is reported in 3 boys, aged 7 to 12 years, followed at the Yale Child Study Center, New Haven, CT. All three reported subjective tension relieved after hair-pulling from the scalp, and one also pulled and ate his eyebrows and eyelashes. Symptoms abated slowly or diminished in two, despite continuation of MPH; TT persisted in one after switching to imipramine. In a clinic for TT, affected boys had greater withdrawal and social problems than girls. Boys were more likely to suffer from ADHD and to be exposed to stimulant therapy. (Martin A, Scahill L, Vitulano L, King RA. Stimulant use and trichotillomania. I Am Acad Child Adolesc Psychiatry April 1998;37:349-350). (Respond: Andres Martin MD, Yale Child Study Center, New Haven, CT).

COMMENT. Tics and compulsive behaviors are well known complications of stimulant therapy for ADHD. Trichotillomania, a further side-effect of MPH to be aware of, has been seen occasionally in our own clinic for ADHD where relatively low doses of MPH are usually prescribed.

Retrospective review of treatment outcome for 63 patients with trichotillomania is reported from the Department of Psychiatry, Massachusetts General Hospital, Charlestown, MA 02129. (Keuthen NJ, O'Sullivan RL, Goodchild P et al. Am I Psychiatry April 1998;155:560-561). Mean age at onset was 12 years and age at follow up was 33 years. The patients ( $92 \%$ female, $8 \%$ male) had been treated for 6 years: $57(90 \%)$ received behavioral treatment, $46(73 \%)$ medication, and 41 